\begin{tabular}{ll}
\hline \hline MINING AND METALLURGY INSTITUTE BOR & ISSN: 2334-8836 (Štampano izdanje) \\
UDK: 622 & ISSN: 2406-1395 (Online) \\
\hline \hline
\end{tabular}

\title{
CHANGES IN Pt-Rh CATALYSTS IN THE WORKING ENVIRONMENT****
}

\begin{abstract}
The surface reconstruction on rhodium-platinum catalyst gauzes has been examined using the scanning electron microscope techniques. The nucleation and growth of large cage-like features, developed on the gauze surfaces during operation in the ammonia oxidation process, were studied in detail. It is concluded that a vapor phase mechanism involving transport of platinum oxide is responsible for the observed reaction, and the reason why this process operates only over a limited range of temperature and pressure is explained. Some comments are also made on the related reconstruction observed on gauzes, used during the production of hydrogen cyanide by the Andrussow process.

Keywords: platinum, platinum catalyst gauze
\end{abstract}

\section{INTRODUCTION}

Rhodium-platinum gauzes serve as catalysts for the oxidation of ammonia during production of nitric acid and for manufacture of hydrogen cyanide. The former, which is based upon the reaction

$$
4 \mathrm{NH}_{3}+5 \mathrm{O}_{2} \rightarrow 4 \mathrm{NO}+6 \mathrm{H}_{2} \mathrm{O}
$$

has given rise to several papers previously published here [1-4], and manufacture of hydrocyanic acid from methane, ammonia and air by the Andrussow process

$$
2 \mathrm{CH}_{4}+2 \mathrm{NH}_{3}+3 \mathrm{O}_{2} \rightarrow 2 \mathrm{HCN}+6 \mathrm{H}_{2} \mathrm{O}
$$

has also been reported [5].

There have been many studies of the surface reconstruction processes which take place when platinum and rhodium-platinum gauzes are used in such catalytic reactions $[6,7]$. Flytzani-Stephanopoulos and Schmidt have reviewed the available literature on thermal etching and morphological changes [8-10]. Most studies have been carried out on pure platinum, with more limited work on rhodium-platinum. Features observed include facets, pits and more extensive cagelike growths. The latter are particularly common under commercial plant operating conditions and therefore merit special attention.

A number of questions remain unanswered from the previous investigations. The mechanism for the nucleation and growth of the cage-like structures is not clear, and the reasons why they are observed only over a limited range of temperature and gas mixtures are not explained. Also their relation to the faceting and pitting observed

\footnotetext{
* Mining and Metallurgy Institute, Zeleni Bulevar 35, Bor, Serbia

** Innovation Center Faculty of Technology and Metallurgy, University of Belgrade, Karnegijeva 4, Belgrade, Serbia

${ }^{* * * *}$ The research results presented in this paper are the result of technological development project $T R 34029$ "Development of production technology of Pd catalyst-catchers to reduce losses of platinum in high temperature catalysis processes", funded by the Ministry of Education, Science and Technological Development.
} 
at high temperatures is not understood. Furthermore, the effect of the presence of rhodium on the reconstruction process has not been studied in detail. Identical gauzes are used in hydrogen cyanide production. These run at higher temperatures and they also face and heavily reconstruct. It has never been fully explained why their reconstructions differ, nor why there is a much lower rate of metal loss in this process-whereas metal loss from ammonia oxidation gauzes is 13 per cent ammonia (corresponding to operating temperatures of 650 to $1200^{\circ} \mathrm{C}$ ) for times from 0.5 to 15 hours. Gauze temperatures where measured by pyrometry and conversion efficiencies by wet chemical analysis. A scanning electron microscope was used to study the surface microstructural changes occurring on 10 per cent rhodium-platinum gauzes, with some work being carried out on pure platinum gauzes for comparison.

\section{OBSERVATION THE SURFACES}

The results exposing rhodium-platinum gauzes to 6,8 10 and 12 per cent ammoniaair mixtures in the miniature reactor for fifteen hours show in Figure 1. The reconstruction process occurs only over a limited range of gas mixtures. It is particularly interesting to note that at 6 per cent ammonia, the catalytic reaction virtually stopped after only four hours, leaving a herringbone-type of structure on the surface. After operation in 12 per cent ammonia, the gauze surface was smooth with angular holes and cavities. Only at intermediate ammonia concentrations did extensive surface reconstruction occur. All the effects occurred at slightly lower ammonia levels than in a commercial plant, apparently due largely to differences in heat dissipation conditions in the miniature reactor.

The nucleation of reconstruction was studied using a shorter exposure time of two hours. Figure 3 shows the role of re-crystallization and grain boundaries. The asreceived gauze shows surface markings due to wire drawing. However, during pretreatment with a hydrogen torch the gauze re-crysta- llizes from its drawn texture, and grain boundary grooves become clearly visible. The following exposure for two hours in the reactor in 10 per cent ammonia, deep cavities develop along grain boundaries, while similar exposure in 13.5 per cent ammonia results in a smooth more rounded surface.

The progressive development with time of the cage-like growths, including the encroachment into grain interiors, can be seen in Figure 4, which shows the effects of exposure for $0.5,1,2$ and 4 hours in an air 8 per cent ammonia mixture. After only half an hour the previously smooth re-crystallized surface shown in Figure 2 (b) has started to reconstruct, Figure 3 (a), this seeming to occur most extensively on some preferredorientation grains. Figure 3 (b) shows the build up of the growths on these crystals. It is interesting to note the part played in propagating the reconstruction into grain interiors by the intersection of thermal facets and grain boundary grooves. Figures 3 (c) and 3 (d) show clearly that the reconstruction spreads out from these intersection points. The surface is finally completely covered by the cage-like growths as in Figure 1 (b).

The larger pilot plant was used to compare pure platinum and rhodium-platinum alloy catalyst gauzes. This allowed accurate observation of the two types of catalyst materials under identical operating conditions. The pilot plant gave same type of reconstruction for a given gas mix as a commercial plant, with a rate of reconstructions somewhat faster than that of a commercial plant but slower than for the miniature laboratory reactor. The reconstruction in the case of pure platinum gauzes was significantly faster than that for identically treated alloy gauzes. For example, Figures 4 (a) and 4 (b) show the microstructures observed on the two types of gauze after a two hour exposure to a 10 per cent ammonia mixture. It is possible that the presence of rhodium on surface layer of catalyst restricts the rate of platinum evaporation, so reducing the vapor transport processes. This is considered below. 

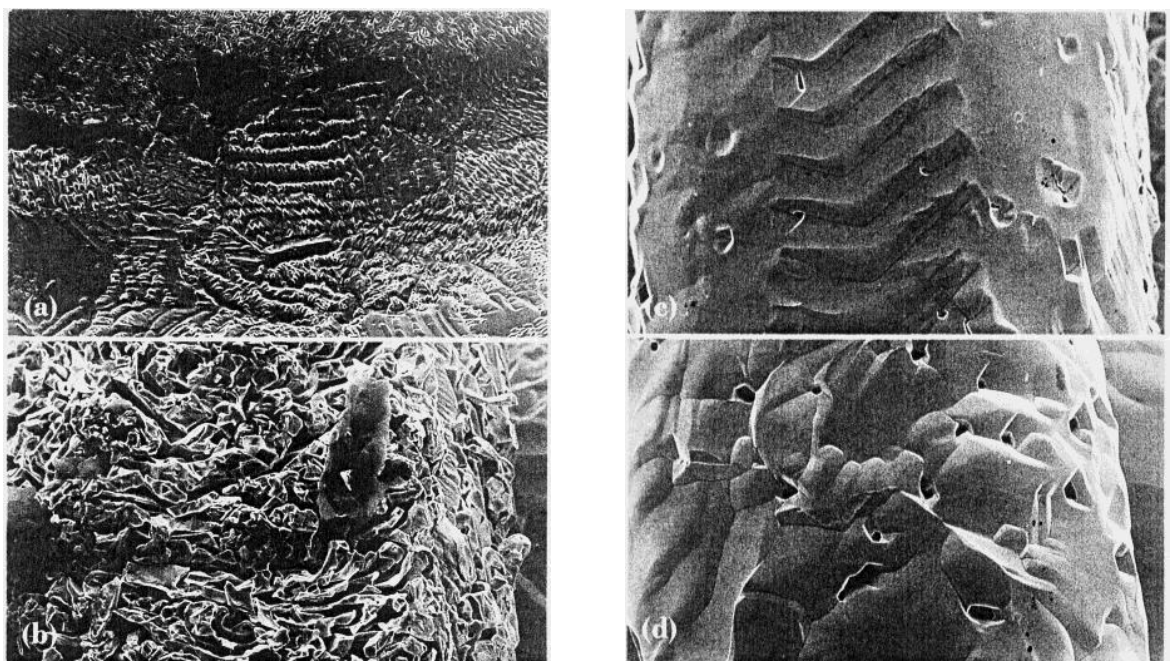

Fig. 1 These gauzes, which were exposed to a range of gas mixtures during operation for 15 hours in a miniature reactor, demonstrate that the changes in surface structure are influenced by the gas mixture: a) air-6 per cent ammonia, this catalyst became inactive during operation,

b) air-8 per cent ammonia, c) air-10 per cent ammonia, d) air-12 per cent ammonia, x1000
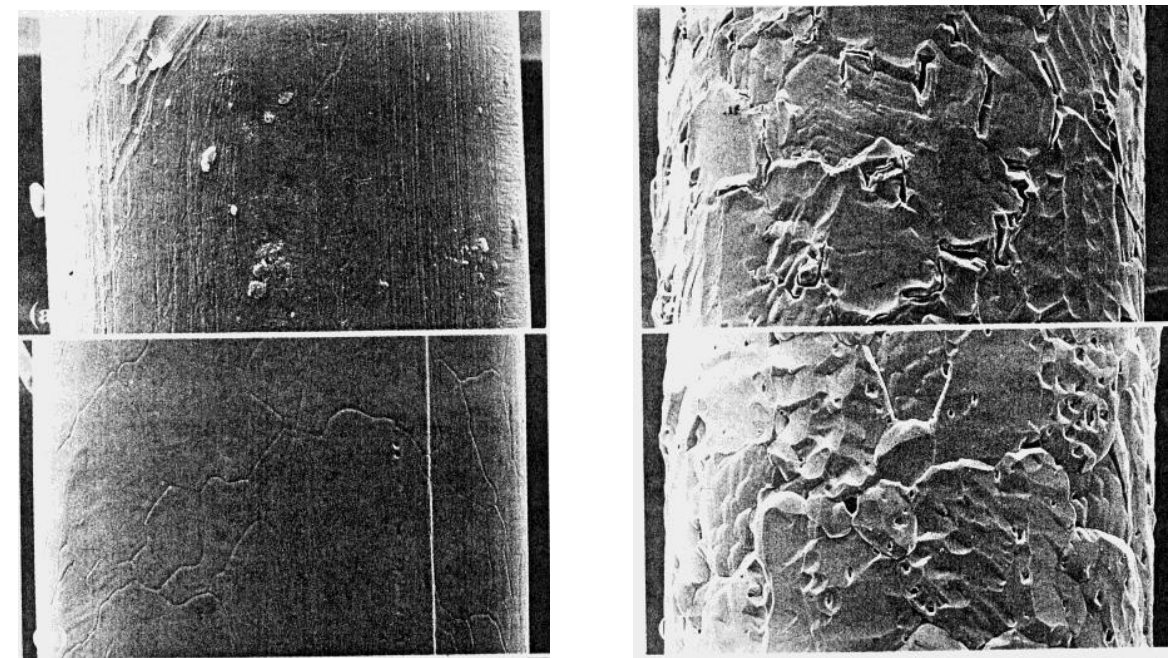

Fig. 2 The nucleation of the reconstruction process was observed on gauzes after two hours in a miniatures reactor. a) Drawing striations are visible on the as-received gauze, but pretreatment in

a hydrogen flame causes re-crystallization $b$ ) when the grain boundaries become visible.

Exposure to air-10 per cent ammonia c) results in development of deep cavities along grain boundaries, while in air-13 per cent ammonia d) more rounded holes develop and the surface is smoother, $x 1000$ 

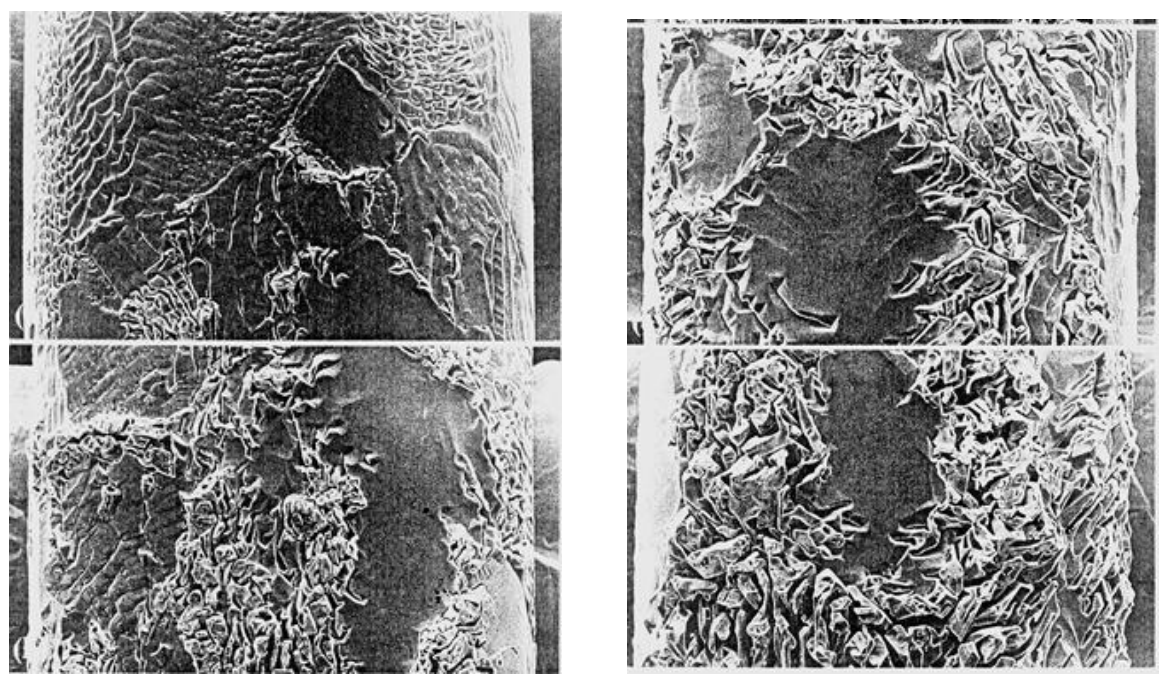

Fig. 3 On rhodium-platinum gauzes exposed to air-8 per cent ammonia the progressive build up of the reconstructing surface can be seen with increasing time, until the surface becomes completely covered by the cage-like, growths, a) 1/2 hour, b)1 hour, c) 2 hours and d) 4 hours, x1000

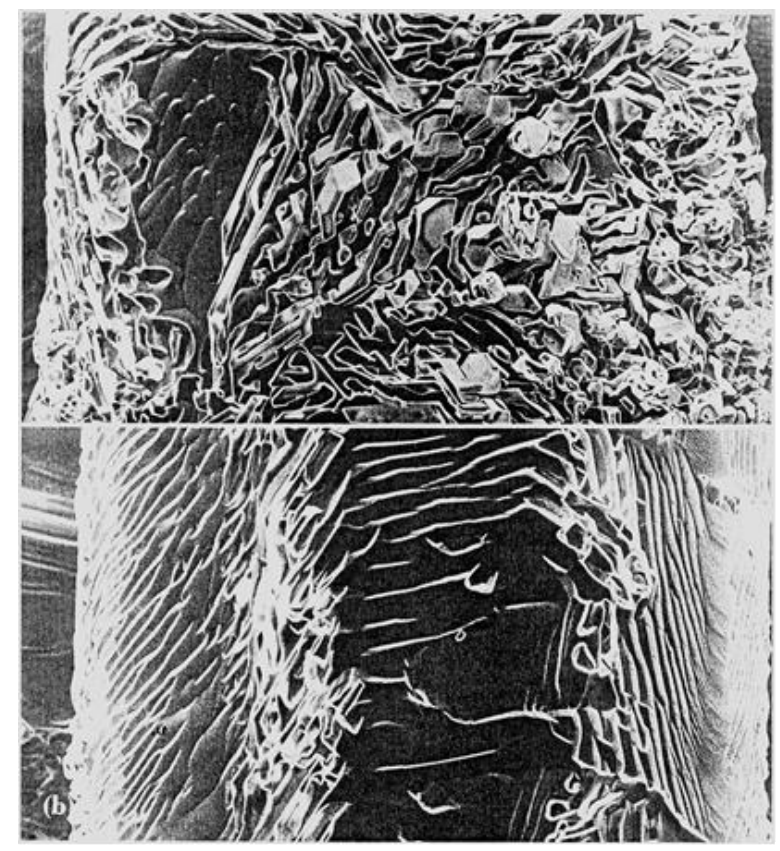

Fig. 4 After reaction in the pilot plant for two hours in an air-10 per cent ammonia mixture, it is apparent that the rate of reconstruction the surfaces of pure platinum and 10 per cent rhodium-platinum are markedly different. In each case the leading face of the third gauze in a pack is shown a) pure platinum, b) rhodium-platinum, x1600 


\section{RESULTS AND DISCUSSION}

The high vapor pressure of $\mathrm{PtO}_{2}$ compared to that of platinum [11-14], along with the observations of weight losses from operational gauzes - and hence the need for catchment gauzes (II) - indicate that there is substantial $\mathrm{PtO}_{2}$ volatilization in the ammonia oxidation process. A vapor phase mechanism for reconstruction is therefore likely, as first proposed by Schmidt and colleagues [15-18]. This model has been developed further, to explain the microstructural features of reconstruction and their dependence on conditions such as gas composition and temperature [19,20]. Consider the boundary between two grains, where a groove will develop on heating simply due surface tension effects. The feed gas contains excess oxygen and the catalytic reaction is very efficient so most of ammonia will be oxidised on initial contract with the outer surface of gauze. The gas reaching the bottom of the grain boundary groove will therefore be more strongly oxidizing than the gas on surface. Platinum oxide will form here preferentially, and will diffuse outwards, to where it meets a more reducing atmosphere, and so platinum will be deposited on the outer surface. Thus the grooves will deepen, and the surface will build up, resulting in the hollow cage-like growths seen on reconstructed gauzes, the process being driven by gradients in oxygen potential. The intersections between thermal facets on the grain surfaces and grain boundary grooves form particularly potent sites for the nucleation and development of the surface growths, since these are the most deeply recessed points on the gauze surfaces.

To understand why the reconstruction occurs only over a limited range of temperature and gas mixtures, the main physical processes taking place on the gauzes have to be considered:
- Platinum oxide vapor formation, migration and decomposition

- The selective oxidation of the rhodium species

- Thermal faceting

- The formation of grain boundary grooves

- Surface diffusion

- Bulk diffusion in both the metal and the oxide.

\section{CONCLUSION}

The extent of each process is dependent on the reaction conditions, the vapour transport process dominating over only a limited range of these conditions. If the temperature is too low (low ammonia content in the gas stream), there is insufficient $\mathrm{PtO}_{2}$ vapor pressure, so the dominant process is the selective oxidation of rhodium to form $\mathrm{Rh}_{2} \mathrm{O}_{3}$. Under these conditions, the catalyst is rapidly deactivated. If the temperature is too high (high ammonia content), then the surface and bulk diffusion are greatly enhanced, leading to a smoothing out of the surface features and a consequent large reduction the surface area. The lower rate of reconstruction observed in the case of rhodium-platinum gauzes suggests that the partial vapor pressure of $\mathrm{PtO}_{2}$ over the alloy is lower than over pure platinum. This would help to explain the reduced weight losses observed commercially when the alloy gauzes are used.

\section{REFERENCES}

[1] Pielaszek, Platinum Metals Rev., 28(3) (1984) 109-114.

[2] A. R McCabe, G. D. W. Smith, Platinum Metals Rev. 27(1) (1983) 19-25.

[3] A. E. Heywood, Platinum Metals Rev., 26(1) (1982) 28-32. 
[4] F. Sperner, W. Hohmann, Platinum Metals Rev., 20(1)( 1976) 12-20.

[5] J. M. Pirie, Platinum Metals Rev., 2 (1) (1958) 7-11.

[6] J. A. Busby, A. G. Knapton, A.E.R. Budd, Proc. Fertiliser Society, 1978, pp.169.

[7] L. D. Schmidt, D. Luss, F. Catal., 22(2) (1971) 269-279.

[8] M. Flytzani-Stephanopoulos, L. D. Schmidt, Prog. Surf, Sci., 9 (3) (1979) 83-111.

[9] A. R. McCabe, G. D. W. Smith, Platinum Metals Rev., 32(1) (1988) 11-18

[10] A. S. Darling, Int. Metall. Rev., 18 (3) (1973), 91-122.

[11] H. Holzmann, Platinum Metals Rev., 13 (1) (1969) 2-8.

[12] R. W. McCabe, T Pignet, L. D. Schmidt, F. Catal., 32 (1) (1974) 114-126.

[13] M. Flytzani-Stephanopoulos, S. Wong and L.D. Schmidt, F. Catal, 49 (1) (1977) 51-82

[14] A. R. McCabe and G.D.W. Smith, $8^{\text {th }}$ International Congress on Catalysis, Berlin (West), Germany, Publ VerlagChemie, Berlin 1984, Vol. 4, pp. 7384.
[15] L. Hannevold, O. Nilsek, A. Kjshus, H. Fjellray, Applied Catalysis A: General, 284 (1-2) (2005)163-176.

[16] L. Hannewold, Applied Catalysis A: General, 284 (1-2) (2005)185-192.

[17] R. Kraehnert, M. Baerns, Applied Catalysis A: General, 327(1)(2007)73-81

[18] V. Meille., Applied Catalysis A: General, 315(2006)1-17

[19] I. B. Chatterj, J. B. Joshi, Chemical Engineering Journal, 125(3)(2007) 149-163.

[20] A. Kolodziej, S. Lojewska, Chemical Engineering and Processing, 48(3)(2009) 816-822.

[21] J. Cher, B. Lim, EW. P. Lee, Y. Xia, Chemical Engineering and Processing 4(2009)81-95.

[22] B. Trumić, D. Stanković, S. Dimitrijević, A. Ivanović, L. Gomidželović, S. Marjanović, Copper 39(2)(2014) 89-94.

[23] B. Trumic, L. Gomidželović, A. Ivanovic, S. Dimitrijevic, S. Marjanovic, V. Krstić, D. S. Stankovic, Copper 40(1)(2015) 17-24. 